\title{
Proteasome inhibition upregulates Bim and induces caspase-3-dependent apoptosis in human mast cells expressing the Kit D816V mutation
}

\author{
C Möller Westerberg ${ }^{\star, 1,2}$, H Hägglund ${ }^{2,3}$ and G Nilsson ${ }^{1,2}$
}

The majority of patients with systemic mastocytosis exhibit a D816V mutation in the activating loop of the Kit receptor expressed on mast cells. The Kit ligand regulates mast cell survival by transcriptional repression of the proapoptotic BH3-only protein Bim and by promoting Bim phosphorylation that makes it vulnerable for proteasomal-dependent degradation. We investigated here whether prevention of Bim degradation by a proteasomal inhibitor, MG132, would induce apoptosis in mast cells with the D816V mutation. Human umbilical cord blood-derived mast cells (CBMCs) with wild-type (wt) Kit and two different subclones of the human mast cell line-1 (HMC-1) were used for the study: HMC-1.1 with the V560G mutation in the juxtamembrane domain and HMC-1.2 carrying the V560G mutation together with the D816V mutation. MG132 at $1 \mu \mathrm{M}$ induced apoptosis in all cell types, an effect accompanied by increased BH3-only proapoptotic protein Bim. The raise of Bim was accompanied by caspase-3 activation, and a caspase-3 inhibitor reduced MG132-induced apoptosis. Further, MG132 caused a reduction of activated Erk, a negative regulator of Bim expression, and thus Bim upregulation. We conclude that decreased phosphorylation and increased levels of Bim overcome the prosurvival effect of the D816V mutation and that the results warrant further investigations of the clinical effects of proteasomal inhibition in systemic mastocytosis.

Cell Death and Disease (2012) 3, e417; doi:10.1038/cddis.2012.157; published online 15 November 2012

Subject Category: Cancer

Mastocytosis is a myeloproliferative disease that is characterized by an abnormal accumulation of mast cells in various tissues, for example, bone marrow, skin and spleen. The disease exists in many variants and WHO has classified it into two main variants: cutaneous mastocytosis and systemic mastocytosis (SM), which is further divided into several subgroups. ${ }^{1}$ Patients with indolent SM can be treated with antimediator drugs, whereas no effective treatment exists today for those with aggressive mastocytosis or mast cell leukemia. ${ }^{2,3}$ The majority of patients with SM (more than $80 \%$ ) harbor an activating mutation in c-kit, the gene coding for Kit, which is the receptor for stem cell factor (SCF). The most common mutation ( $>90 \%$ ) is the $\mathrm{D} 816 \mathrm{~V}$ mutation that causes substitution in the activating loop of an aspartic residue with a valine residue, leading to an autoactivation of the receptor. ${ }^{4,5}$

In view of the fact that the gain-of-function mutations in Kit is so common in SM and has a key role in the pathogenesis, the D816V mutation represents an attractive drug target for SM. The small molecular inhibitor imatinib mesylate (Gleevec, Novartis, Basel, Switzerland) has been tested in both preclinical and clinical studies on D816V mutations and found to be ineffective. ${ }^{6,7}$ This is in sharp contrast to the strong effect of Gleevec on Kit with mutations in the juxtamembrane region that is common in gastrointestinal stromal tumors. ${ }^{8}$ Several other potential drug candidates with the ability to either inhibit the
D816V mutation directly or to inhibit downstream targets that regulate mast cell proliferation and/or survival has recently been tested. ${ }^{3}$ These drugs include tyrosine kinase inhibitors such as dasatinib (SPRYCEL, Bristol-Myers Squibb, Princeton, NJ, USA) ${ }^{9,10}$ Exel-0862, ${ }^{11}$ SU-5416, ${ }^{12}$ PKC412, ${ }^{13,14}$ AMN107 ${ }^{15}$ and AP23464. ${ }^{16}$ The ligand-independent autoactivation of Kit that is caused by the D816V mutation leads to the activation of several downstream signaling pathways, which is why inhibition of any of those could be a plausible target. Inhibition of the mammalian target of rapamycin (mTOR) by rapamycin was described to induce apoptosis in mast cells with D816V mutations. ${ }^{17}$ Likewise, cells with the D816V mutation have a constitutively active NF- $\kappa \mathrm{B}$, and inhibition of this pathway suppresses proliferation in cells with mutated Kit. ${ }^{18}$

Mutation in the catalytic domain of $c$-kit has an impact on multiple cellular functions, including proliferation, migration, adhesion, mediator release and sustained survival. We have previously demonstrated that in mast cells with wild-type (wt) Kit, SCF regulates survival by repressing the levels of the proapoptotic BH3-only protein Bim. ${ }^{19}$ The effect of SCF is dual, affecting both the transcription of Bim by inactivation of its transcription factor $\mathrm{FOXO} 3 \mathrm{a}$ and by phosphorylation of $\mathrm{Bim},{ }^{19}$ which leads to ubiquitination and proteasomal degradation of the protein. ${ }^{20,21}$ We therefore hypothesized that targeting the proteasome may inhibit degradation of Bim in

\footnotetext{
${ }^{1}$ Clinical Immunology and Allergy Unit, Department of Medicine, Karolinska Institutet, Stockholm, Sweden; ${ }^{2}$ Mastocytosis Centre at Karolinska University Hospital and Karolinska Institutet, Stockholm, Sweden and ${ }^{3}$ Department of Hematology, Karolinska University Hospital, Karolinska Institutet, Stockholm, Sweden

*Corresponding author: C Möller Westerberg, Clinical Immunology and Allergy Unit, Department of Medicine, Karolinska Institutet, KS L2:04, 171 76 Stockholm, Sweden. Tel: +46 8517 721 70; Fax: +46 8335 724; E-mail: Christine.Moller@ki.se

Keywords: MG132; Velcade; apoptosis; mast cells; mastocytosis; Bim

Abbreviations: CBMCs, human umbilical cord blood-derived mast cells; HMC-1, human mast cell line-1; SM, systemic mastocytosis; SCF, stem cell factor Received 07.6.12; revised 19.9.12; accepted 20.9.12; Edited by H-U Simon
} 
mast cells with the D816V mutation and thereby induce apoptosis in the cells. For these studies, we used cord bloodderived mast cells (CBMCs) with wt Kit, and two variants of the human mast cell line-1 (HMC-1): ${ }^{22} \mathrm{HMC}-1.1$ that has a mutation in the juxtamembrane region (V560G) and HMC-1.2 with the V560G mutation together with the D816V mutation in the catalytic domain. ${ }^{5,23}$ Besides Bim we also investigated the expression levels of Puma, another BH3-only protein that we recently demonstrated to be involved in mast cell apoptosis. ${ }^{24}$ Here we provide evidence that the proteasome inhibitor MG132 increases the expression of Bim, reduces Erk and Kit activation and causes a caspase-3-dependent apoptosis, even in mast cells with D816V mutations.

\section{Results}

MG132 inhibits cell growth of HMC-1.1, HMC-1.2 and CBMCs. HMC-1.1 and HMC-1.2 cell lines with V560G and V560G + D816V Kit mutations, respectively, were cultured in the presence of the proteasome inhibitor MG132 and the cell growth was enumerated by calculating the number of viable cells. We found that the cell number dropped dramatically both in HMC-1.1 and HMC-1.2 cells, as well as in SCFtreated CBMCs with wt Kit (Figure 1). The percentage of input cell number after $48 \mathrm{~h}$ treatment with MG132, 1 or $10 \mu \mathrm{M}$, had declined from $100 \%$ at time point zero to $29.9 \pm 14.0 \%$ and $33.6 \pm 18.3 \%$ in $\mathrm{HMC}-1.1 ; 50.5 \pm 11.7 \%$ and $40.8 \pm 12.6 \%$ in $\mathrm{HMC}-1.2 ; 37.6 \pm 1.9 \%$ and $3.2 \pm 0.9 \%$ in CBMCs, respectively. At $72 \mathrm{~h}$, very few viable cells remained in the cultures.

Treatment with MG132 induces apoptosis in mast cells with mutated Kit. We next investigated if the effect of MG132 was due to cytotoxicity. We could not detect the release of lactate dehydrogenase (LDH) from MG132 (1 and $10 \mu \mathrm{M})$-treated HMC-1.1, HMC-1.2 or CBMCs, suggesting that MG132 is not cytotoxic to the cells (data not shown). To explore if the loss in cell number was due to apoptosis, the cells were stained with propidium iodide (PI) and Annexin V. After $48 \mathrm{~h}$ of treatment with MG132, a clear induction of apoptosis could be observed in all three mast cell types (Figure 2). The percentage of living HMC-1.1 cells, HMC-1.2 cells and CBMCs after MG132 treatment, 1 or $10 \mu \mathrm{M}$, for $72 \mathrm{~h}$ was $20.6 \pm 4.9 \%$ and $18.6 \pm 1.8 \%$ in $\mathrm{HMC}-1.1$; $41.5 \pm 8.9 \%$ and $18.3 \pm 12.0 \%$ in HMC-1.2; $49.0 \pm 16.1 \%$ and $17.3 \pm 0.5 \%$ in CBMCs, respectively (Figure 2 ). With time the amount of apoptotic cells gradually increased in MG132-treated cells; thus, apoptosis was both dose- and time-dependent.

Velcade has a pronounced effect on HMC-1.2 cell survival. The proteasome inhibitor Velcade (bortezomib), used in clinical applications, was tested for its efficacy on HMC-1.1, HMC-1.2 and CBMCs. A dose-dependent decrease in cell survival was detected for all cell types tested (Figure 3). However, the sensitivity to the drug differed between the three cell types. At $48 \mathrm{~h}$, Velcade caused pronounced apoptosis in HMC-1.2, intermediate cell death in HMC-1.1 and the CBMCs were the least sensitive to the drug at all concentrations tested (Figure 3).
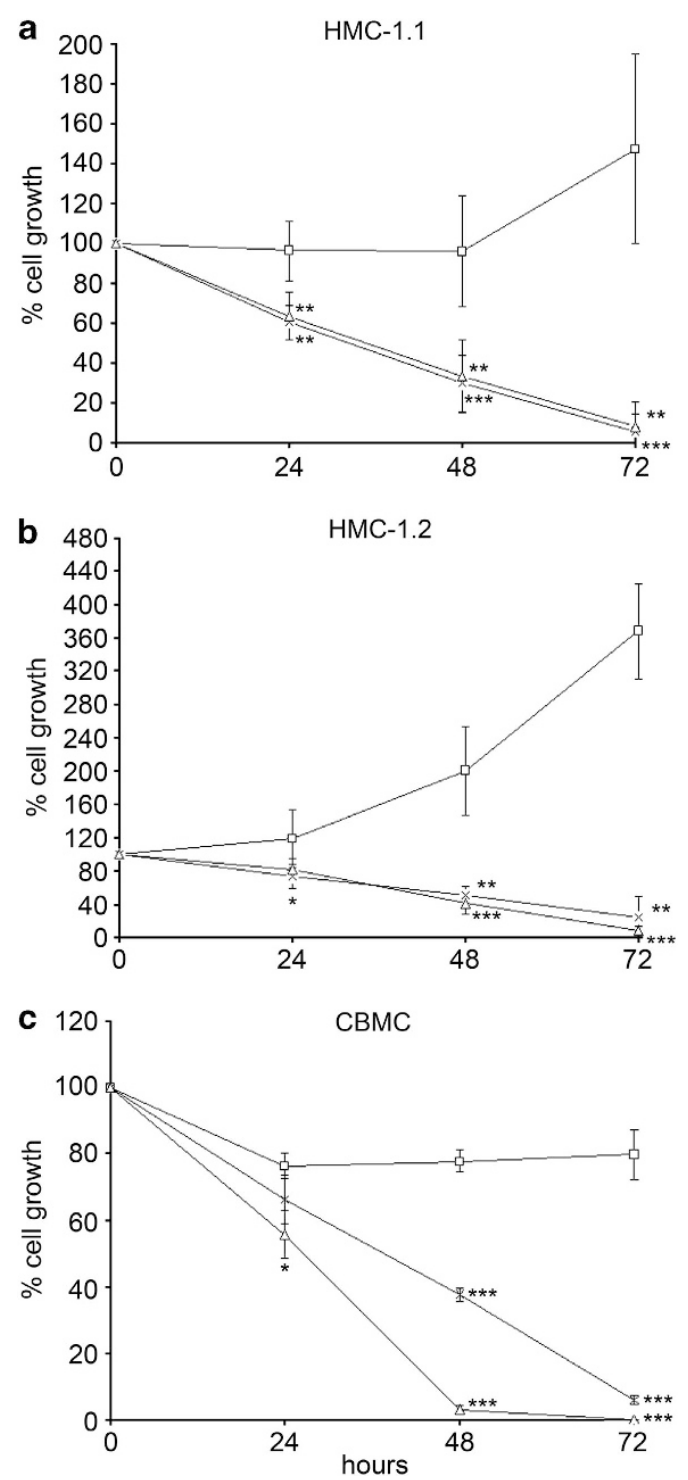

Figure 1 MG132 inhibits cell growth of human mast cells with activated Kit. Kinetic curves of MG132-treated (a) HMC-1.1 (V560G mutation), (b) HMC-1.2 (V560G and D816V mutations) and (c) CBMCs (activated with SCF), where $\square$ indicates control cells, $\times 1 \mu \mathrm{M}$ MG132 and $\Delta 10 \mu \mathrm{M}$ MG132-treated cells. Viable cells were quantified by trypan blue exclusion criteria. Mean \pm S.D., $n=3$. ${ }^{\star} P<0.05,{ }^{* *} P<0.01$ and ${ }^{* \star *} P<0.001$

Bim and Puma expression and Erk and Kit activation is changed upon MG132 treatment. We have earlier demonstrated that Bim and Puma are involved in regulating growth factor deprivation-induced apoptosis in murine mast cells, ${ }^{24,25}$ and that SCF regulates mast cell survival through inhibition of Bim. ${ }^{19}$ To examine if the drop in cell number and induction of apoptosis after MG132 treatment was accompanied by induction of the $\mathrm{BH}$-only proteins Bim and Puma, we performed western blot analyses. At steady state, some Bim protein could be detected in HMC-1.1 and HMC-1.2 cells, where Bim appears to be in a phosphorylated state (Figure 4). A prominent increase in Bim expression was seen already after $8 \mathrm{~h}$ of MG132 treatment in all mast cells tested 

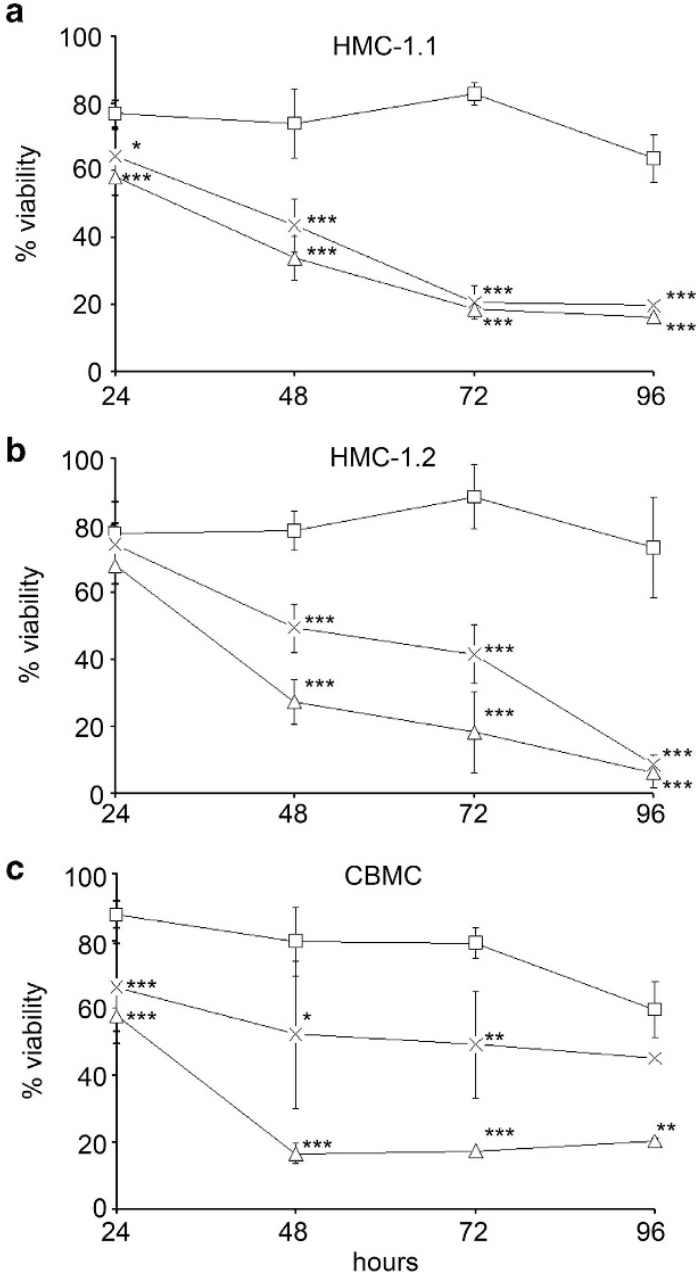

Figure 2 Apoptosis in MG132-treated mast cells. Effect of MG132 on the induction of apoptosis in (a) HMC-1.1, (b) HMC-1.2 and (c) CBMCs, where $\square$ indicates control cells, $\times 1 \mu \mathrm{M}$ MG132 and $\triangle 10 \mu \mathrm{M}$ MG132-treated cells. Apoptotic and necrotic cells were measured by Annexin V/PI staining and flow cytometric analysis after 24, 48, 72 and $96 \mathrm{~h}$ treatment with MG132. Data plotted represent the mean of viable cells \pm S.D. of three to six experiments performed in duplicates. ${ }^{*} P<0.05,{ }^{* *} P<0.01$ and ${ }^{* * *} P<0.001$

(data not shown) and the expression levels increased over time (Figure 4). We observed a difference in the phosphorylation of Bim in MG132-treated HMC-1 cells and CBMCs. In cells with mutated Kit, MG132 treatment leads to induction of Bim that was primarily not phosphorylated, whereas in CBMCs most of Bim was in phosphorylated state.

In contrast to the strong upregulation of Bim upon MG132 treatment, an increase in Puma was not detected. After $24 \mathrm{~h}$ of MG132 treatment, the Puma levels were comparable to background control or a slight decrease of Puma was seen after $10 \mu \mathrm{M}$ MG132 treatment in HMC-1.2 (Figure 4). In CBMCs, a small increase of Puma was detected at $1 \mu \mathrm{M}$, but at $10 \mu \mathrm{M}$ of MG132 the levels were back to background or slightly lower (Figure 4).

We have previously shown that SCF regulates Bim through the PI3-kinase and MEK/MAPK signaling pathway. ${ }^{19}$ Recently, MG132 treatment was also shown by others to cause reduced Erk activation in glioma cells. ${ }^{26}$ To explore the
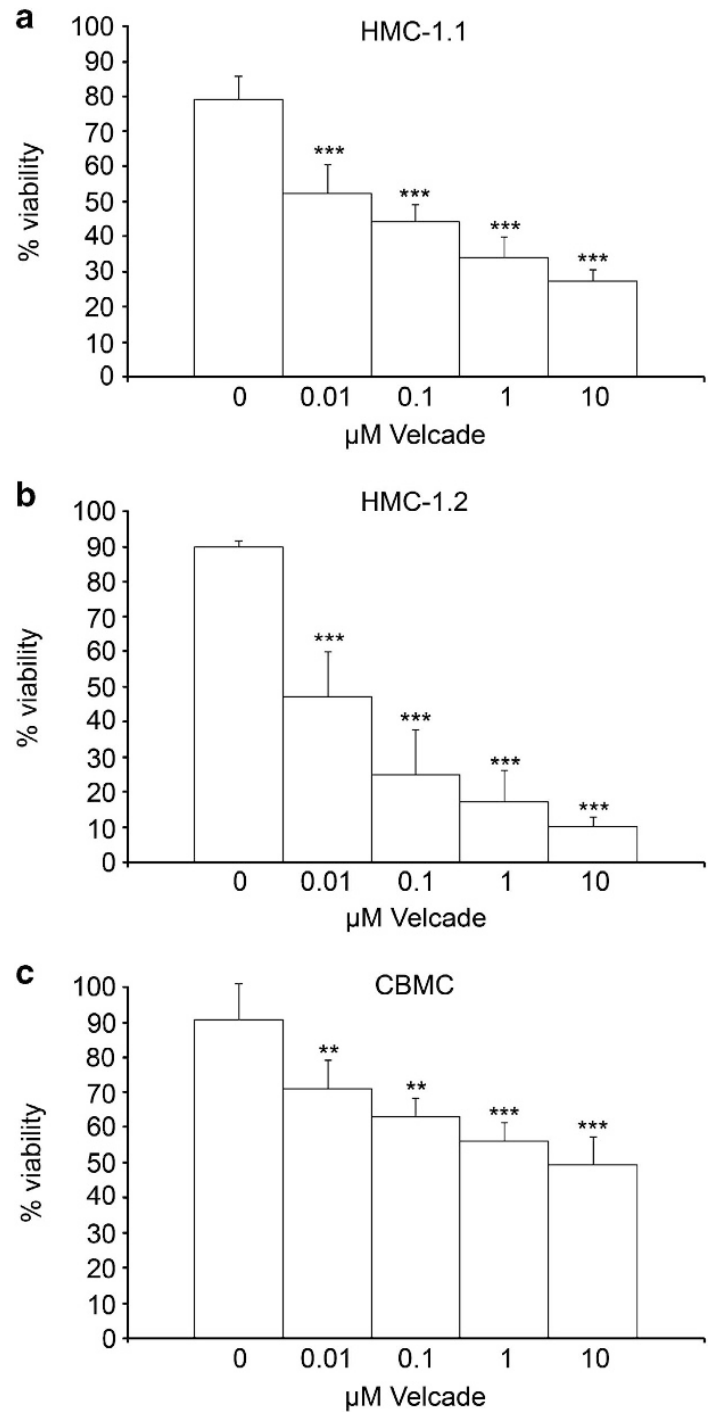

Figure 3 Apoptosis in mast cells treated with Velcade. The effect of Velcade $(0.01,0.1,1$ and $10 \mu \mathrm{M})$ on the induction of apoptosis was seen in (a) HMC-1.1, (b) HMC-1.2 and (c) CBMCs. Data represent the mean \pm S.D. of two to four experiments carried out in duplicates. ${ }^{*} P<0.05,{ }^{* \star} P<0.01$ and ${ }^{* \star *} P<0.001$

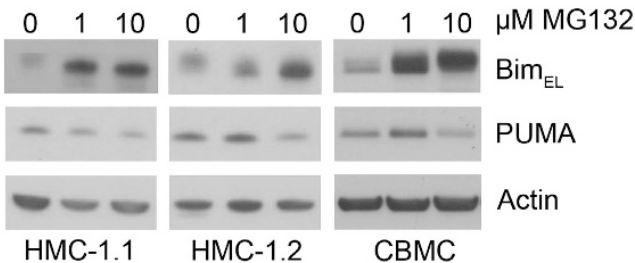

Figure 4 Induction of the proapoptotic protein Bim but not Puma after MG132 treatment. Western blot analysis of Bim and Puma in HMC-1.1, HMC-1.2 and CBMCs, treated with MG132 at 0 (ctrl), 1 and $10 \mu \mathrm{M}$ for $24 \mathrm{~h}$. Probing for actin served as a loading control. The results shown are representative of three independent experiments

involvement of MEK/MAPK signaling in MG132-mediated Bim regulation, both $\mathrm{HMC}-1$ subclones were pretreated with $40 \mu \mathrm{M}$ of the MEK inhibitor PD98059 before adding MG132. The 
inhibitor reduced Erk activation in both $\mathrm{HMC}-1.1$ and $\mathrm{HMC}-1.2$ cells (Figure 5). MG132 alone also decreased Erk phosphorylation, and in combination with PD98059, this reduction was even more prominent. Restricted Erk was accompanied by a decrease of Bim phosphorylation and thus an increase in Bim expression.

As MG132 alone had an effect on the phosphorylation of Erk, we investigated if MG132 could also affect the autophosphorylated Kit in HMC-1.1 and HMC-1.2. After $24 \mathrm{~h}$ treatment with MG132 (1 and $10 \mu \mathrm{M})$, both HMC-1 cell lines exhibited reduced phosphorylation of Kit where the HMC-1.1 cells were more sensitive, with reduced phosphorylation of Kit at already $1 \mu \mathrm{M} \mathrm{MG} 132$ treatment (data not shown).

Thus, not only does the proteasome inhibitor MG132 inhibit Bim protein degradation but it also seems to facilitate increased expression of Bim by inhibiting the phosphorylation of Erk and Kit, and thus receptor activation.

MG132-induced caspase-3 activation and apoptosis is reduced by pretreatment with a caspase inhibitor. Induction of apoptosis via the Bcl-2-family-regulated pathway, where the $\mathrm{BH} 3$-only proteins are active, finally leads to the activation of effector caspases, including caspase-3. ${ }^{27}$ Activation of caspase-3 can be determined by western blot analysis of cleavage of procaspase-3. Proteasome inhibition by MG132 treatment for $24 \mathrm{~h}$ led to caspase-3 cleavage in HMC-1.1, HMC-1.2 and CBMCs (Figure 6a). This suggests that increased levels of Bim leads to caspase- 3 activation and cell death also in mast cells with autoactivated Kit.

Caspase activity can be blocked by the z-VAD-fmk inhibitor. To investigate if apoptosis upon MG132 treatment was induced via activation of caspase-3, we included z-VAD-fmk to the cultures and measured cell viability after $48 \mathrm{~h}$. As shown in Figures 6b, cell viability was increased in MG132-treated cultures where $100 \mu \mathrm{M} z-V A D$-fmk was included, suggesting that apoptosis is induced, at least in part, via a caspase-3dependent pathway.

siRNA targeting Bim reduces MG132-induced apoptosis in mast cells. To investigate the importance of Bim in mediating cell death after MG132 treatment, HMC-1.1 and HMC-1.2 were transfected with siRNA targeting Bim or a control siRNA. Both HMC-1.1 and HMC-1.2 transfected with Bim siRNA survived better than the cells transfected with control siRNA upon MG132 treatment (Figures 7a and b). Bim protein expression in both HMC-1.1 and HMC-1.2 was also markedly reduced compared with cells transfected with control siRNA (Figures 7c and d).

\section{Discussion}

This study demonstrates that the proteasome inhibitor MG132 impedes with cell growth and causes cell death in normal CBMCs and neoplastic HMC-1 mast cells. The cell death is mediated through the mitochondrial pathway of apoptosis by induced Bim expression, caspase- 3 activation and repressed Kit and Erk phosphorylation.

The survival of mast cells is dependent on the continued delivery of SCF by the surrounding stromal cells. However, a

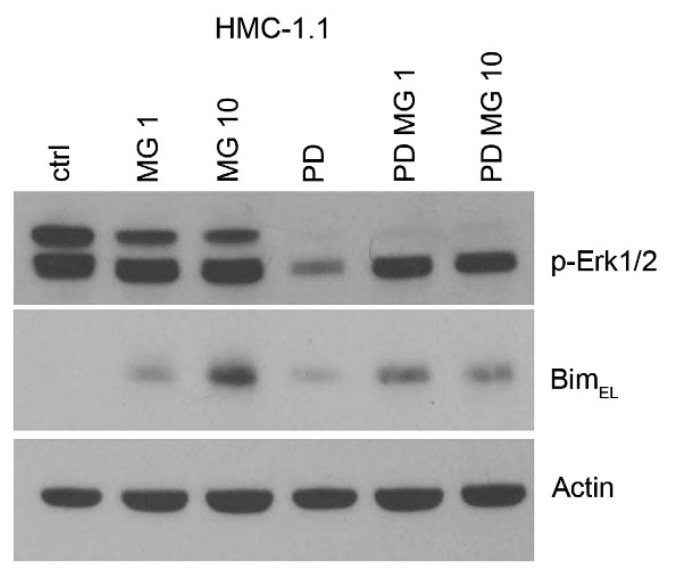

HMC-1.2

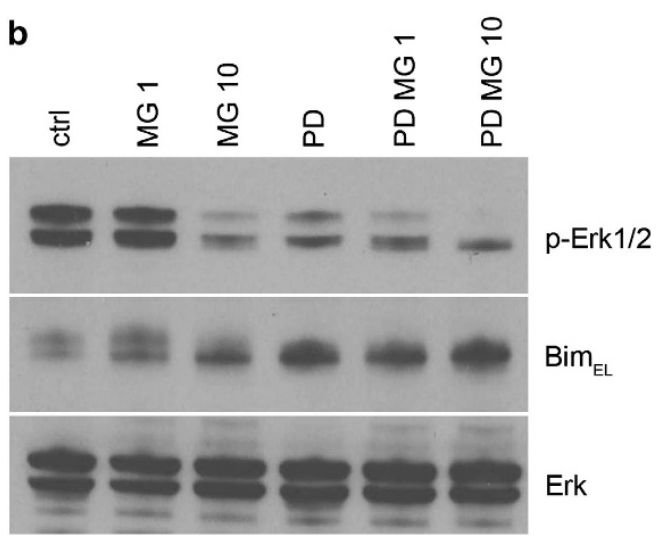

Figure 5 MG132 reduces phosphorylation of Erk1/2 and increases Bim protein. Western blot analysis of phospho-Erk and Bim $24 \mathrm{~h}$ after MG132 treatment in combination with the MEK/MAPK inhibitor PD98059. (a) HMC-1.1 and (b) HMC-1.2 treated with MG132 at 0 (ctrl), 1 and $10 \mu \mathrm{M} \pm$ PD98059. Probing for actin or Erk served as a loading control. The results shown are representative of three independent experiments

neoplastic mast cells in mastocytosis have developed a system to overcome SCF dependence and still survive. Most mastocytosis patients have a point mutation or mutations in $c-k i t$, the gene encoding the SCF receptor $\mathrm{Kit}^{3}$ This mutation makes Kit autoactivated, even in the absence of SCF, which enables the receptor to keep up the prosurvival signaling as well as mast cell survival and proliferation. The results of our study show that in mast cells with wt Kit and in HMC-1 with autoactivated Kit, MG132 can inhibit cell growth and induce cell death. The suppression of cell survival is restricted not only to mast cells with the D816V mutation but is also seen with the other V560G mutation and in SCF-stimulated CBMCs with wt Kit.

SM patients with the D816V mutation in c-kit are usually poor responders to therapeutics. ${ }^{28}$ Small molecular inhibitors have been tested with various results, but still new improved therapies are needed. ${ }^{13,29}$ As the proteasome inhibitor MG132 in our study reduced cell survival in all mast cells tested, we also tested Velcade, a proteasome inhibitor used in the clinic. Velcade is mainly used in multiple myeloma as a means to overcome resistance and induce sensitivity when 

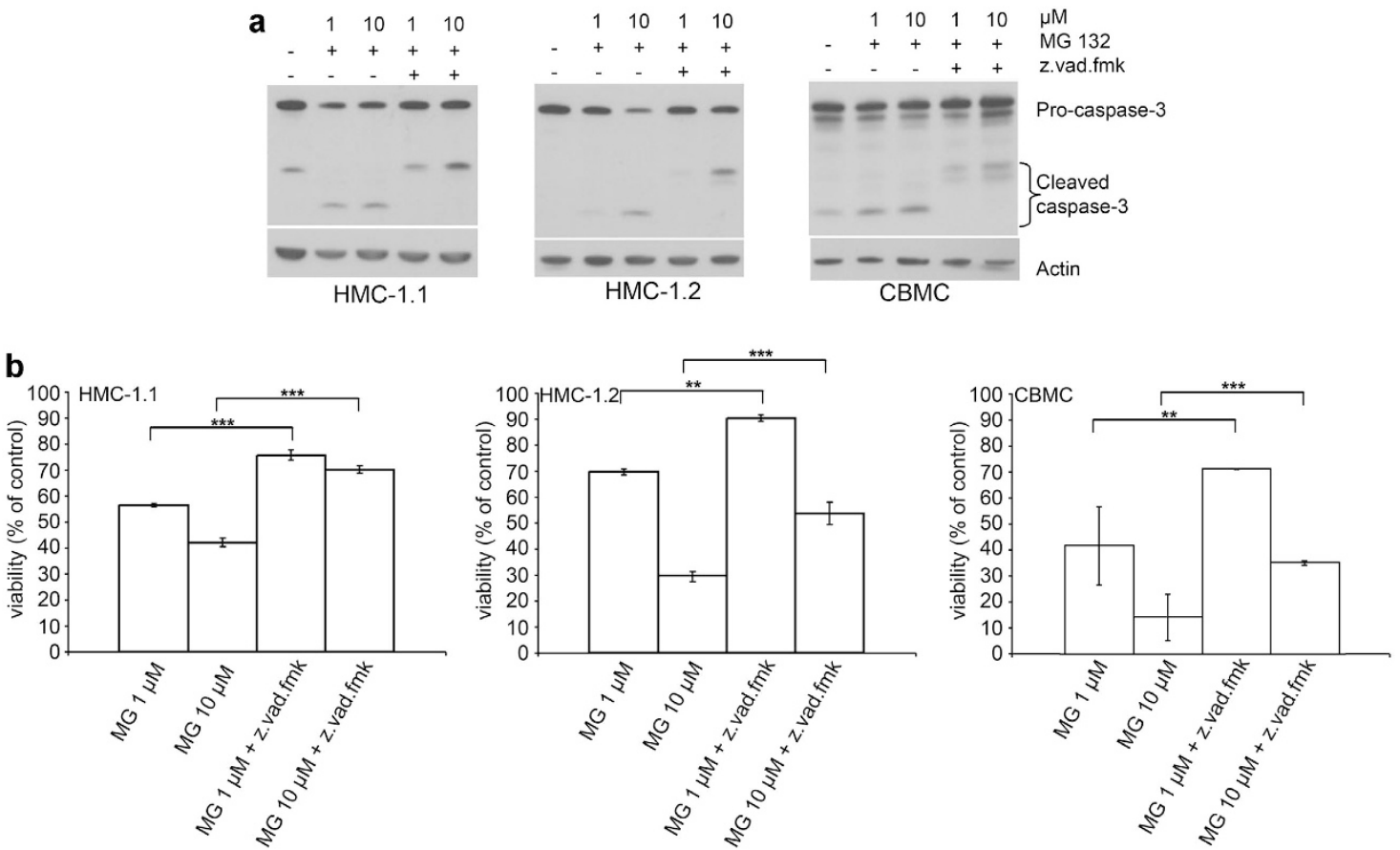

Figure 6 MG132 treatment causes caspase-3 protein activation and apoptosis that can be attenuated by caspase inhibition. An activation of procaspase-3 into activated caspase-3 was determined by western blot in HMC-1.1, HMC-1.2 and CBMCs treated with 1 and $10 \mu \mathrm{M}$ of MG132 for $24 \mathrm{~h}$. Pretreatment with $100 \mu \mathrm{M}$ of the caspase inhibitor z-VAD-fmk reduced caspase-3 protein activation after $24 \mathrm{~h}$ (a) and cell viability after $48 \mathrm{~h}(\mathbf{b})$, enumerated by Annexin V/PI staining and flow cytometric analysis, expressed as the percent of untreated control cells that was set to $100 \%$. The results shown are representative of three independent experiments. ${ }^{* *} P<0.01$ and ${ }^{* * *} P<0.001$

used in combination with a variety of other chemotherapeutic agents. $^{30}$ In our study, HMC-1.2 mast cells, with both the V560G and D816V mutations in c-kit, were most sensitive to the drug compared to HMC-1.1 with the V560G mutation. The CBMCs with wt Kit were the least responsive cells. This is in accordance with previous preclinical studies that have demonstrated that neoplastic cells are more susceptible to the cytotoxic effects of proteasome inhibition than normal cells. ${ }^{31}$ One proposed mechanism behind this is that malignant cells take advantage of the proteasome to overcome proliferative regulation and escape apoptosis. Moreover, tumor cells are highly proliferative and thereby have more protein synthesis, and thus accumulation of proteins would make them more vulnerable to proteasome inhibition. This also corresponds to the sensitivity of the different mast cells in our study where the HMC-1.2 cell line is highly proliferative and at the same time most sensitive to proteasome inhibition compared with the slow proliferating HMC-1.1 cell line and CBMCs with low/no proliferation.

Although SCF has a major role in supporting mast cell survival and proliferation, the mechanisms behind this are only partially understood. We have earlier reported that mouse mast cell survival and apoptosis is regulated by the BH3-only proteins Bim and Puma. ${ }^{19,24}$ We have also demonstrated that SCF regulates the expression of Bim on two levels, both through repression of its transcription by phosphorylation of the transcription factor Foxo3A and by phosphorylation of Bim, which makes it vulnerable for proteasomal degradation. ${ }^{19}$ In this study, MG132 caused an increase of Bim protein, but had low effects on Puma in
CBMC, HMC-1.1 cells and HMC-1.2 cells. A decrease in phosphorylated Bim was also detected. Our results are in agreement with a previous publication by Aichberger et al. ${ }^{14}$ where they also demonstrated an effect of Bim and mast cell survival after proteasomal inhibition. In addition to their study, we also explored the signaling pathways involved in MG132mediated mast cell apoptosis. We investigated the MEK/ MAPK signaling pathway that we have earlier seen regulate Bim. ${ }^{19}$ MG132 treatment led to decreased phosphorylation and thus reduced activation of Erk in both HMC-1.1 and HMC1.2. In combination with MG132, the MEK/MAPK inhibitor PD98059 induced more Bim than when used alone. Thus, MG132 functioned beyond proteasome inhibition and somehow affected the mast cell signaling. This result is in accordance with another study where they found that the Erk and Akt signaling pathway is downregulated by MG132 in glioma cells. ${ }^{26}$ Proteasome inhibitors have also been demonstrated to induce apoptosis in neoplastic cells when used as a single agent and induce sensitivity to other chemotherapeutic agents in combination. ${ }^{32}$ Interestingly, MG132 also reduced Kit phosphorylation, which to our knowledge has not been reported before.

To provide evidence that $\mathrm{Bim}$ is involved in regulating mast cell survival upon MG132 treatment, the expression of Bim was silenced by siRNA transfection. After transfection, the ability of MG132 to induce apoptosis in the HMC-1 cell lines was markedly reduced compared with cells transfected with control siRNA. Mast cells transfected with Bim siRNA survived significantly better than the cells transfected with control siRNA upon treatment with 1 or $10 \mu \mathrm{M}$ MG132 treatment, but 

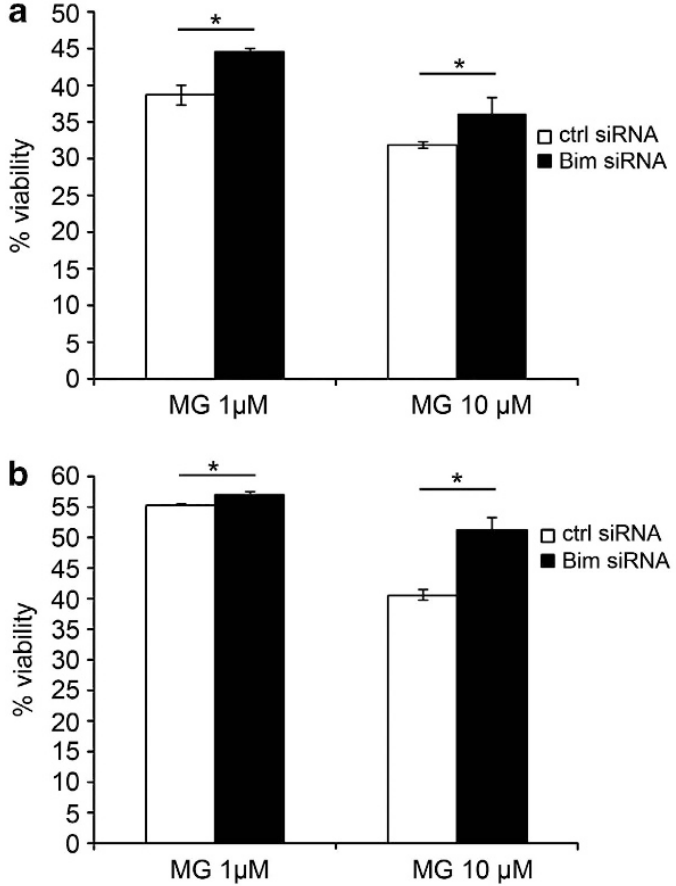

c ctrl siRNA Bim siRNA

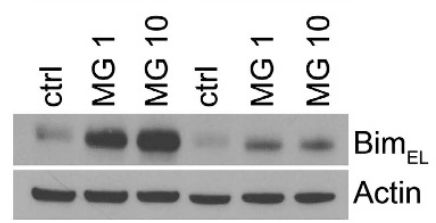

d ctrl siRNA Bim siRNA

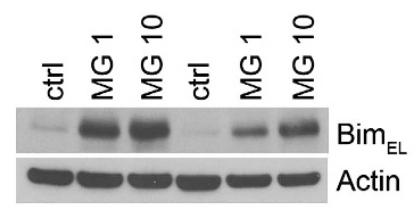

Figure 7 siRNA targeting Bim reduces MG132-induced apoptosis and Bim protein expression (a, c) HMC-1.1 and (b, d) HMC-1.2 cells transfected with Bim siRNA have increased survival and reduced Bim protein expression compared with cells transfected with control siRNA upon 1 and $10 \mu \mathrm{M}$ MG132 treament for 24 to $48 \mathrm{~h}$. Cell viability was enumerated by Annexin V/PI staining and flow cytometric analysis, expressed as the percent of untreated control cells that was set to $100 \%$. The results shown are representative of three independent experiments. Probing for actin served as a protein loading control. ${ }^{*} P<0.01$

still a high degree of apoptosis could be measured. These data, together with only partial protection of the pancaspase inhibitor z-VAD-fmk from MG132-induced cell death, suggest that additional so far unknown mechanism/s are involved in MG132-induced mast cell apoptosis, which still needs to be investigated.

Since the proteasomal pathway is critical for the degradation of about $80 \%$ of intracellular proteins and proteasome inhibition has been demonstrated to restrict growth of various cancer cell lines, it has emerged as a promising target for anticancer therapies. Bim is known to be degraded through the proteasomal pathway and has been identified as an important tumor suppressor protein in different myeloid neoplasms. ${ }^{14,21,33-35}$ Moreover, Bim is often suppressed by disease-related oncogenes in nepolastic cells, ${ }^{21,34,35}$ and to overcome this, by proteasomal inhibition, could be a way to regulate different types of malignancies. Hence, this might be a way to regulate signaling from the autoactivated Kit in mastocytosis, and to overcome drug resistance, especially in SM patients with few/no effective therapies.

\section{Conclusions}

Our results demonstrate that neoplastic mast cells are sensitive to proteasome inhibition. This could be used to improve treatment of mastocytosis patients, especially those with SM.

\section{Materials and Methods}

Mast cell cultures. After informed consent from the donors, human umbilical cord blood was obtained and used for the development of CBMCs as described previously. ${ }^{36,37}$ Mast cells were either developed by culturing the mononuclear cell population for 8-10 weeks in RPMI 1640 medium (Sigma Chemicals Co., St. Louis, MO, USA) supplemented with 10\% FCS (Gibco, Paisley, UK), $50 \mathrm{ng} / \mathrm{ml}$ SCF (Biosource International Inc., Camarillo, CA, USA) and $10 \mathrm{ng} / \mathrm{ml} \mathrm{IL-6}$ (PeproTech, London, UK), or by culturing CD34-selected cells in serum-free StemPro medium (Gibco) supplemented with $30 \mathrm{ng} / \mathrm{ml}$ IL-3 (for the first week only), $50 \mathrm{ng} / \mathrm{ml} \mathrm{SCF}$ and $10 \mathrm{ng} / \mathrm{ml}$ IL-6. Mast cell development was evaluated by staining for the mast cell-specific serine proteinase tryptase, as described previously. ${ }^{37}$ The purity of mast cells exceeded $95 \%$ when used in the experiments. The use of CBMCs was approved by the ethics committee at the Uppsala University Hospital.

The human mast cell lines, HMC-1.1 and HMC-1.2, were maintained in IMDM (Sigma) supplemented with $10 \%$ FCS, $2 \mathrm{mM}$ L-glutamine, $100 \mathrm{IU} / \mathrm{ml}$ penicillin/ streptomycin and $1.2 \mathrm{mM}$ monothioglycerol (Sigma). ${ }^{23}$ The cells were passed twice a week.

Analysis of cell growth. For cell growth measurements, the cells were seeded at $1 \times 10^{6}$ cells per $\mathrm{ml}$. The number of living cells produced each day for 3 days $(0-72 h)$ was determined by trypan blue exclusion.

LDH cytotoxicity test. Cells were exposed in 96-well plates at a density of $0.5 \times 10^{6}$ cells per ml. Two controls were included for each cell line and primary cells. One control consisted of cells in medium only (spontaneous release), whereas the second control was a measurement of maximum LDH release. Cells were incubated with MG132 (Calbiochem, Merck Chemicals Ltd, Nottingham, UK) $(0.1,110$ and $100 \mu \mathrm{M})$ in a humidified atmosphere, $5 \% \mathrm{CO}_{2}$ and $37^{\circ} \mathrm{C}$, and after $24 \mathrm{~h}$, the samples were analyzed by flow cytometry or by absorbance measurements at $492 \mathrm{~nm}$.

Analysis of cell survival and apoptosis. To monitor apoptosis, HMC1.1, HMC-1.2 and CBMCs were stained with PI $(2 \mu \mathrm{g} / \mathrm{ml})$ plus FITC-conjugated Annexin V $(0.3 \mu \mathrm{g} / \mathrm{ml})$ and analyzed in a FACScan (Becton Dickinson, San Jose, CA, USA). The number of viable cells after $6,24,48,72$ and $96 \mathrm{~h}$ of MG132 (Calbiochem), Velcade (Johnson \& Johnson, New Brunswick, NJ, USA), proteasome inhibitor z-VAD-fmk (Calbiochem) and Bim siRNA treatment was counted by FACScan analysis. As a control, the viability of the mast cells was measured in the absence of MG132 or Velcade.

Western blot. The cells were treated with 0,1 or $10 \mu \mathrm{M}$ MG132 and/or with $40 \mu \mathrm{M}$ of the MEK/MAPK inhibitor PD98059 (Calbiochem Novabiochem, La Jolla, CA, USA) for the indicated periods of time. After incubation, the mast cells were lysed in SDS lysis buffer (62.5 mM Tris-HCl (pH 6.8), 2\% (w/v) SDS, 10\% glycerol, $50 \mathrm{mM} \mathrm{DTT}, 0.01 \%$ (w/v) bromphenol blue), and sonicated on ice. The phosphorylation and/or the total amount of proteins of interest were studied by western immunoblotting using a NuPAGE Bis-Tris western gel (NOVEX, Life Technologies, CA, USA). After electrophoresis, the proteins were electroblotted onto nitrocellulose membranes (Hybond ECL; GE Healthcare, Uppsala, Sweden). After transfer, filters were blocked in Tris-buffered saline containing $5 \%(\mathrm{w} / \mathrm{v})$ non-fat dry milk and $0.1 \%$ Tween-20. Membranes were then incubated with 
primary antibody overnight at $4{ }^{\circ} \mathrm{C}$, and with HRP-conjugated secondary antibody for $1 \mathrm{~h}$ at room temperature. The proteins were visualized using the enhanced chemiluminescence (ECL) system (LumiGLO; Cell Signaling, Danvers, MA, USA) and exposure to a Hybond ECL film (GE Healthcare). The following antibodies were used: anti-Puma (NT) antibody (ProSci, Poway, CA, USA), anti-Bim antibody (Affinity BioReagents, Golden, CO, USA), anti-actin antibody (Sigma), phosphor-Tyr (PY99) and anti-Erk antibodies (Santa Cruz Biotechnology Inc. Santa Cruz, CA, USA), and anti-phospho-Erk1/2 and anti-caspase-3 antibodies (Cell Signaling).

Bim siRNA mediated inhibition of Bim gene expression. To inhibit Bim gene expression, HMC-1 cells were transfected using Bim and control siRNA nucleotides, human BCL2L11 GENOME SMART pool siRNA and non-targeting pool siRNA (Dharmacon Inc., Lafayette, CO, USA). siRNA at a concentration of $100 \mathrm{nM}$ was introduced into the HMC-1 cell lines through the use of a Nucleoporator, using the primary mammalian fibroblast basic nucleofector kit (VPI1002); program X-001 (Amaxa AG, Cologne, Germany), all according to the manufacturer's protocol. At 24 hours post-transfection, viable cells were enriched by removing dead cells with the MACS dead cell removal kit (Miltenyi Biotec, Bergisch Gladbach, Germany) according to the manufacturer's protocol. The viable cells were treated with 0,1 and $10 \mu \mathrm{M}$ MG132 for 24 (HMC-1.2) to $48 \mathrm{~h}$ (HMC-1.1) and the number of viable cells were enumerated by Annexin V/PI staining and flow cytometric analysis, and cell lysates were prepared for protein expression analysis by western blot.

Statistical analysis. Statistical analysis was performed using the Student's $t$-test, where the $P$-values, indicate the statistically significant differences.

\section{Conflict of Interest}

The authors declare no conflict of interest.

Acknowledgements. We thank Mrs. Agnetha Beinhoff for expert help with the mast cell cultures. This work was supported by the Swedish Cancer Foundation Swedish Research Council-Medicine, The Center for Allergy Research at Karolinska Institutet, Consul Th C Berghs Foundation, Ollie and Elof Ericsson's Foundation, King Gustav V's 80-years Foundation, Hans von Kantzows foundation, Ellen, Walter and Lennart Hesselman's foundation, Magnus Bergvalls Foundation and Karolinska Institutet.

1. Valent $P$, Akin $C$, Sperr WR, Mayerhofer M, Fodinger M, Fritsche-Polanz R et al. Mastocytosis: pathology, genetics, and current options for therapy. Leuk Lymphoma 2005; 46: $35-48$

2. Valent $P$, Akin $C$, Escribano L, Fodinger M, Hartmann $\mathrm{K}$, Brockow $\mathrm{K}$ et al. Standards and standardization in mastocytosis: consensus statements on diagnostics, treatment recommendations and response criteria. Eur J Clin Invest 2007; 37: 435-453.

3. Orfao A, Garcia-Montero AC, Sanchez L, Escribano L: REMA. Recent advances in the understanding of mastocytosis: the role of KIT mutations. Br J Haematol 2007; 138: 12-30.

4. Furitsu $\mathrm{T}$, Tsujimura $\mathrm{T}$, Tono $\mathrm{T}$, Ikeda $\mathrm{H}$, Kitayama $\mathrm{H}$, Koshimizu $\mathrm{U}$ et al. Identification of mutations in the coding sequence of the proto-oncogene c-kit in a human mast cell leukemia cell line causing ligand-independent activation of c-kit product. J Clin Invest 1993; 92: $1736-1744$

5. Nagata $\mathrm{H}$, Worobec AS, Oh CK, Chowdhury BA, Tannenbaum S, Suzuki $\mathrm{Y}$ et al Identification of a point mutation in the catalytic domain of the protooncogene c-kit in peripheral blood mononuclear cells of patients who have mastocytosis with an associated hematologic disorder. Proc Natl Acad Sci USA 1995; 92: 10560-10564.

6. Ma Y, Zeng S, Metcalfe DD, Akin C, Dimitrijevic S, Butterfield JH et al. The C-KIT mutation causing human mastocytosis is resistant to STI571 and other KIT kinase inhibitors; kinases with enzymatic site mutations show different inhibitor sensitivity profiles than wild-type kinases and those with regulatory-type mutations. Blood 2002; 99: 1741-1744.

7. Zermati $\mathrm{Y}$, De Sepulveda $\mathrm{P}$, Feger F, Letard S, Kersual J, Casteran $\mathrm{N}$ et al. Effect of tyrosine kinase inhibitor STI571 on the kinase activity of wild-type and various mutated c-kit receptors found in mast cell neoplasms. Oncogene 2003; 22: 660-664.

8. Heinrich MC, Blanke CD, Druker BJ, Corless CL. Inhibition of KIT tyrosine kinase activity: a novel molecular approach to the treatment of KIT-positive malignancies. J Clin Oncol 2002; 20: 1692-1703.

9. Schittenhelm MM, Shiraga S, Schroeder A, Corbin AS, Griffith D, Lee FY et al. Dasatinib (BMS-354825), a dual SRC/ABL kinase inhibitor, inhibits the kinase activity of wild-type juxtamembrane, and activation loop mutant KIT isoforms associated with human malignancies. Cancer Res 2006; 66: 473-481.
10. Shah NP, Lee FY, Luo R, Jiang Y, Donker M, Akin C. Dasatinib (BMS-354825) inhibits KITD816V, an imatinib-resistant activating mutation that triggers neoplastic growth in most patients with systemic mastocytosis. Blood 2006; 108: 286-291.

11. Pan J, Quintas-Cardama A, Kantariian HM, Akin C, Manshouri T, Lamb P et al. EXEL0862, a novel tyrosine kinase inhibitor, induces apoptosis in vitro and ex vivo in human mast cells expressing the KIT D816V mutation. Blood 2007; 109: 315-322.

12. Kosmider O, Denis N, Dubreuil P, Moreau-Gachelin F. Semaxinib (SU5416) as a therapeutic agent targeting oncogenic Kit mutants resistant to imatinib mesylate. Oncogene 2007; 26: 3904-3908.

13. Gleixner KV, Mayerhofer M, Aichberger KJ, Derdak S, Sonneck K, Bohm A et al. PKC412 inhibits in vitro growth of neoplastic human mast cells expressing the D816V-mutated variant of KIT: comparison with AMN107, imatinib, and cladribine $(2 \mathrm{CdA})$ and evaluation of cooperative drug effects. Blood 2006; 107: 752-759.

14. Aichberger KJ, Gleixner KV, Mirkina I, Cerny-Reiterer S, Peter B, Ferenc V et al. Identification of proapoptotic Bim as a tumor suppressor in neoplastic mast cells: role of KIT D816V and effects of various targeted drugs. Blood 2009; 114: 5342-5351.

15. Verstovsek S, Akin C, Manshouri T, Quintas-Cardama A, Huynh L, Manley P et al. Effects of AMN107, a novel aminopyrimidine tyrosine kinase inhibitor, on human mast cells bearing wild-type or mutated codon 816 c-kit. Leuk Res 2006; 30: 1365-1370.

16. Corbin AS, Demehri S, Griswold IJ, Wang Y, Metcalf CA III, Sundaramoorthi R et al. In vitro and in vivo activity of ATP-based kinase inhibitors AP23464 and AP23848 against activation-loop mutants of Kit. Blood 2005; 106: 227-234.

17. Gabillot-Carre M, Lepelletier Y, Humbert M, de Sepuvelda P, Hamouda NB, Zappulla JP et al. Rapamycin inhibits growth and survival of D816V-mutated c-kit mast cells. Blood 2006; 108: 1065-1072.

18. Tanaka A, Konno M, Muto S, Kambe N, Morii E, Nakahata T et al. A novel NF-kappaB inhibitor, IMD-0354, suppresses neoplastic proliferation of human mast cells with constitutively activated c-kit receptors. Blood 2005; 105: 2324-2331.

19. Moller C, Alfredsson J, Engstrom M, Wootz H, Xiang Z, Lennartsson J et al. Stem cell factor promotes mast cell survival via inactivation of $\mathrm{FOXO3a-mediated} \mathrm{transcriptional} \mathrm{induction} \mathrm{and}$ MEK-regulated phosphorylation of the proapoptotic protein Bim. Blood 2005; 106: 1330-1336.

20. Ley R, Balmanno K, Hadfield K, Weston C, Cook SJ. Activation of the ERK $1 / 2$ signaling pathway promotes phosphorylation and proteasome-dependent degradation of the $\mathrm{BH} 3$ only protein, Bim. J Biol Chem 2003; 278: 18811-18816.

21. Luciano F, Jacquel A, Colosetti P, Herrant M, Cagnol S, Pages G et al. Phosphorylation of Bim-EL by Erk $1 / 2$ on serine 69 promotes its degradation via the proteasome pathway and regulates its proapoptotic function. Oncogene 2003; 22: 6785-6793.

22. Butterfield JH, Weiler D, Dewald G, Gleich GJ. Establishment of an immature mast cell line from a patient with mast cell leukemia. Leuk Res 1988; 12: 345-355.

23. Sundstrom M, Vliagoftis $H$, Karlberg $P$, Butterfield $J H$, Nilsson $K$, Metcalfe DD et al. Functional and phenotypic studies of two variants of a human mast cell line with a distinct set of mutations in the c-kit proto-oncogene. Immunology 2003; 108: 89-97.

24. Ekoff M, Kaufmann T, Engstrom M, Motoyama N, Villunger A, Jonsson Jl et al. The BH3only protein Puma plays an essential role in cytokine deprivation induced apoptosis of mast cells. Blood 2007; 110: 3209-3217.

25. Alfredsson J, Puthalakath $\mathrm{H}$, Martin $\mathrm{H}$, Strasser A, Nilsson G. Proapoptotic Bcl-2 family member Bim is involved in the control of mast cell survival and is induced together with $\mathrm{Bcl}$ XL upon IgE-receptor activation. Cell Death Differ 2005; 12: 136-144.

26. Ko JK, Choi CH, Kim YK, Kwon CH. The proteasome inhibitor MG-132 induces AIF nuclea translocation through down-regulation of ERK and Akt/mTOR pathway. Neurochem Res 2011; 36: 722-731.

27. Strasser A. The role of $\mathrm{BH} 3-$ only proteins in the immune system. Nat Rev2005; 5: 189-200.

28. Pardanani A, Tefferi A. Systemic mastocytosis in adults: a review on prognosis and treatment based on 342 Mayo Clinic patients and current literature. Curr Opin Hematol 2010: 17: 125-132.

29. Akin C, Brockow K, D'Ambrosio C, Kirshenbaum AS, Ma Y, Longley BJ et al. Effects of tyrosine kinase inhibitor STI571 on human mast cells bearing wild-type or mutated c-kit. Exp Hematol 2003; 31: 686-692.

30. Richardson PG, Sonneveld P, Schuster MW, Irwin D, Stadtmauer EA, Facon T et al. Bortezomib or high-dose dexamethasone for relapsed multiple myeloma. N Engl J Med 2005; 352: 2487-2498.

31. Miasari M, Puthalakath $\mathrm{H}$, Silke J. Ubiquitylation and cancer development. Curr Cancer Drug Targets 2008; 8: 118-123.

32. Dai Y, Rahmani M, Grant S. Proteasome inhibitors potentiate leukemic cell apoptosis induced by the cyclin-dependent kinase inhibitor flavopiridol through a SAPK/JNK- and NFkappaB-dependent process. Oncogene 2003; 22: 7108-7122.

33. O'Reilly LA, Cullen L, Visvader J, Lindeman GJ, Print C, Bath ML et al. The proapoptotic $\mathrm{BH} 3-$ only protein bim is expressed in hematopoietic, epithelial, neuronal, and germ cells. Am J Pathol 2000; 157: 449-461.

34. Kuribara R, Honda H, Matsui H, Shinjyo T, Inukai T, Sugita $\mathrm{K}$ et al. Roles of Bim in apoptosis of normal and Bcr-Abl-expressing hematopoietic progenitors. Mol Cell Biol 2004; 24: $6172-6183$

35. Aichberger KJ, Mayerhofer M, Krauth MT, Vales A, Kondo R, Derdak S et al. Low-level expression of proapoptotic $\mathrm{Bcl}$-2-interacting mediator in leukemic cells in patients with chronic myeloid leukemia: role of $B C R / A B L$, characterization of underlying signaling pathways, and reexpression by novel pharmacologic compounds. Cancer Res 2005; 65: 9436-9444. 
36. Gulliksson M, Palmberg L, Nilsson G, Ahlstedt S, Kumlin M. Release of prostaglandin D2 and leukotriene $\mathrm{C} 4$ in response to hyperosmolar stimulation of mast cells. Allergy 2006; 61: 1473-1479.

37. Nilsson G, Blom T, Harvima I, Kusche-Gullberg M, Nilsson K, Hellman L. Stem cell factordependent human cord blood derived mast cells express alpha- and beta-tryptase, heparin and chondroitin sulphate. Immunology 1996; 88: 308-314. (c) Cell Death and Disease is an open-access journal SOMERELHISRESERVED published by Nature Publishing Group. This work is licensed under the Creative Commons Attribution-NonCommercial-No Derivative Works 3.0 Unported License. To view a copy of this license, visit http://creativecommons.org/licenses/by-nc-nd/3.0/ 